Mongolian Academy of Sciences
Mongolian Journal of Chemistry
Institute of Chemistry \& Chemical Technology

\title{
Hydrocracking of atmospheric distillable residue of Mongolian oil
}

\author{
Ts.Tugsuu $^{1}$, Sugimoto Yoshikazu ${ }^{2}$, B.Enkhsaruul ${ }^{1}$, D.Monkhoobor ${ }^{1}$ \\ ${ }^{1}$ School of Chemistry and Chemical Engineering, NUM, PO Box-46/574, Ulaanbaatar 14201, Mongolia \\ ${ }^{2}$ Energy Technology Research Institute, AIST, 1-1-1, Higashi, Tsukuba, Ibaraki 305-8565, Japan
}

\begin{abstract}
Many catalytic processes to refine heavy part of crude oil have attracted much interest due to declining reserves of light crude oils. This study focused on hydrocracking process of atmospheric distillable residue of Mongolian crude oil in the first time compared to those of other countries. Residue samples were hydrocracked with a commercial catalyst at $450^{\circ} \mathrm{C}, 460^{\circ} \mathrm{C}, 470^{\circ} \mathrm{C}$ for $2 \mathrm{~h}$ under hydrogen pressure of $10 \mathrm{MPa}$. The amount of residual fraction $\left(350^{\circ} \mathrm{C}<\mathrm{BP}\right)$ decreased to $9.4 \mathrm{wt} \%$ by the hydrocracking of atmospheric distillable residue from Tamsagbulag crude oil. When the ME-AR was hydrocracked, the high consumption of hydrogen was related to the lowest $\mathrm{H} / \mathrm{C}$ atomic ratio of feed atmospheric residue. The amount of liquid fractions $\left(\mathrm{BP}<350^{\circ} \mathrm{C}\right)$ including gaseous products increased from $45.4 \mathrm{wt} \%$ to $89.2 \mathrm{wt} \%$, when the reaction temperature increased from $450^{\circ} \mathrm{C}$ to $470^{\circ} \mathrm{C}$. The highest yield of the middle fraction for each sample was observed at temperature of $460^{\circ} \mathrm{C}$. On the other hand, the effect of temperature on the yield of middle fraction was not so high as compared with the yields of other fractions. The contents of n-paraffins on midlle and heavy fractions of TB-AR, DQ-AR were similar, but ME-AR's was around 2 times lower than other after hydrocracking runs.
\end{abstract}

Keywords: Hydrocracking, atmospheric residue, Tamsagbulag crude oil, commercial catalyst, middle fraction

\section{Introduction}

$\mathrm{I}$ $\mathrm{n}$ recent years, considerable attention has been paid to the research on refining process of heavy part of Mongolian crude oils. Mongolian crude oils have small amounts of sulfur [1] and heavy metals [2], which make some troubles to the refining processes of crude oil. Therefore, it is considered that there is a possibility to refine Mongolian crude oil by cheap and efficient technology. On the other hand, Mongolian crude oils contain a large amount of atmospheric residual (52.9 - $69.8 \mathrm{wt} \%)$, which should be converted into light and middle oils in order to produce motor fuels and chemicals $[3,4]$.

The current study has focused on the catalytic hydrocracking process in the atmospheric distillable residue of Mongolian crude oil comparing with those of Chinese and Arabian crude oils at different temperatures under hydrogen pressure of 10 MPa using a commercial cracking catalyst. Our experiments have been carried out at the Hydrocracking Catalyst Laboratory of Advanced Fuel Group, Energy Technology Research Institute (ETRI), National Institute 
Advanced Industrial Science and Technology (AIST), Tsukuba, Japan.

\section{Experimental}

Materials. Three atmospheric distillable residues were used in this work. Mongolian Tamsagbulag crude oil's is coded as TB-AR; Chinese Daqing oil's - as DQ-AR; mixed Middle East crude oil's as ME-AR. The TB oil sample was supplied by "Daqing Tamsag" Company, which is doing a mining operation in Mongolia. Atmospheric distillable residues of DQ-AR and ME-AR were obtained from Japanese refinery. Elemental analysis results of the atmospheric distillable residues are shown in Table 1.

Table 1. Elemental analysis of the atmospheric residues

\begin{tabular}{|c|c|c|c|c|c|}
\hline Samples & $\mathrm{C}, \%$ & $\mathrm{H}, \%$ & $\mathrm{~S}, \%$ & $\mathrm{~N}, \%$ & $\mathrm{H} / \mathrm{C}$ \\
\hline TB-AR & 86.54 & 13.12 & 0.18 & 0.16 & 1.82 \\
\hline DQ-AR & 86.59 & 13.13 & 0.12 & 0.16 & 1.82 \\
\hline ME-AR & 85.55 & 11.85 & 2.47 & 0.13 & 1.66 \\
\hline
\end{tabular}

Hydrocracking test. An atmospheric residue sample was hydrocracked at $450^{\circ} \mathrm{C}, 460^{\circ} \mathrm{C}$ and $470^{\circ} \mathrm{C}$ for 2 hours using a fixed bed reactor that was inserted into an electric furnace with vertically shaking type. The dates in table 2 show the conditions of hydrocracking experiments. About $4 \mathrm{~g}$ of atmospheric distillable residue with $200 \mathrm{mg}$ of commercial catalyst was charged into the reactor, the inner volume of which was $50 \mathrm{ml}$. The reactor was pressurized by hydrogen gas up to $10 \mathrm{MPa}$ at ambient temperature, and then was heated to the prescribed temperature. Reaction temperature was maintained for 2 hours for every run [5].

Table 2. The condition of hydrocracking test

\begin{tabular}{|c|c|c|}
\hline \multirow{2}{*}{ Sample } & Name & TB-AR, DQ-AR, ME-AR \\
\cline { 2 - 3 } & Weight & $4.0 \mathrm{~g}$ \\
\hline \multirow{2}{*}{ Catalyst } & Type & $\mathrm{NiMo} \mathrm{Al}_{2} \mathrm{O}_{3}$ \\
\cline { 2 - 3 } & Weight & $0.2 \mathrm{~g}$ \\
\hline Pressure of hydrogen & $10 \mathrm{MPa}$ \\
\hline \multicolumn{2}{|c|}{ Inner volume of reactor } & $50 \mathrm{ml}$ \\
\hline \multicolumn{2}{|c|}{ Temperature } & $450^{\circ} \mathrm{C}, 460^{\circ} \mathrm{C}, 470^{\circ} \mathrm{C}$ \\
\hline \multicolumn{2}{|c|}{ Reaction time } & 2 hours \\
\hline
\end{tabular}

Analysis. After the reaction, gaseous products were subjected to Gas chromatography coupled with thermal conductivity detector (GC-TCD; Agilent, 6890) to estimate its composition. Then, contents of methane, ethane and propane gases were calculated using a calibration of standard gas samples. Initially, atmospheric distillable residue was separated using by a distillation method to examine quantitatively its fractional composition. The Gas chromatography system coupled with a sulfur chemiluminescence detector (GC-SCD; Agilent 6890) was used to determine the sulfur content. The distillation curve of the liquid product was examined using a GC-FID system (Agilent, model 6890GC) that was equipped with a fused silica column $5 \mathrm{~m}$ long $[5,6]$.

AR - Atmospheric distillable residue of crude oil, Boiling point is over than $350^{\circ} \mathrm{C}$

LF - Light fraction, $<220^{\circ} \mathrm{C}$

MF - Middle fraction, $220^{\circ} \mathrm{C}-350^{\circ} \mathrm{C}$

HF - Heavy fraction, $350^{\circ} \mathrm{C}-500^{\circ} \mathrm{C}$

Bottom - Residue $500^{\circ} \mathrm{C}<$

Figure 1. Flow chart showing the handling of the products for experimental hydrocracking

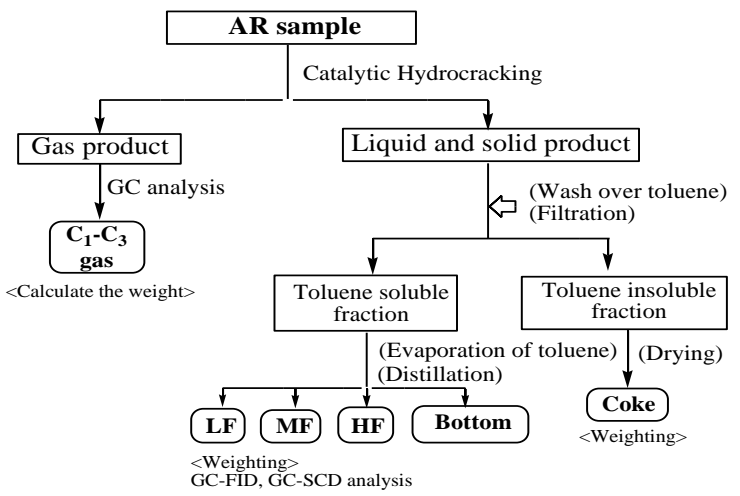

The liquid product was handled as shown in Figure 1. At first, the toluene insoluble fraction (TIF) was extracted from hydrocracking products. The toluene soluble fraction (TS) was recovered after solvent evaporation, and was then divided into four sub fractions by a distillation method: light fraction (LF), middle fraction (MF), heavy 
fraction (HF) and bottom. The separated distinct fractions were weighed to check a material balance including the content of gaseous products.

\section{Results and Discussion}

Table 3 shows the product distribution after the hydrocracking of atmospheric residue at different temperatures for $2 \mathrm{~h}$ under hydrogen pressure of $10 \mathrm{MPa}$ using a fixed bed reactor.

Table 3. The products content after catalytic hydrocracking of the atmospheric residue at different temperatures

\begin{tabular}{|c|c|c|c|c|c|c|c|c|c|}
\hline \multirow[b]{2}{*}{$\frac{\mathscr{v}}{\bar{\Xi}}$} & \multirow[b]{2}{*}{ 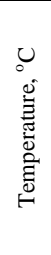 } & \multirow{2}{*}{ 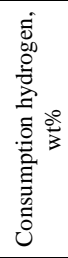 } & \multirow[b]{2}{*}{ 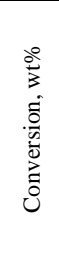 } & \multicolumn{6}{|c|}{ Content of products (wt \%) } \\
\hline & & & & $\begin{array}{l}\tilde{J} \\
0 \\
0 \\
\dot{U} \\
ن\end{array}$ & 岃 & $\sum^{L}$ & 至 & $\begin{array}{l}\tilde{\Xi} \\
\stackrel{0}{0} \\
\text { ๑ }\end{array}$ & $\frac{\ddot{y}}{0}$ \\
\hline \multirow{3}{*}{ 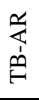 } & 450 & 0.5 & 56.7 & 3.7 & 29.3 & 22.0 & 38.0 & 5.3 & 2.2 \\
\hline & 460 & 0.4 & 74.9 & 5.7 & 43.0 & 26.1 & 23.6 & 1.5 & 0.5 \\
\hline & 470 & 0.9 & 90.6 & 11.4 & 53.9 & 23.6 & 8.6 & 0.8 & 2.6 \\
\hline \multirow{3}{*}{$\begin{array}{l}\frac{1}{1} \\
\dot{d} \\
0\end{array}$} & 450 & 0.4 & 47.9 & 2.8 & 27.9 & 14.8 & 30.8 & $\begin{array}{c}21 . \\
3\end{array}$ & 2.8 \\
\hline & 460 & 0.4 & 69.9 & 5.0 & 37.9 & 24.8 & 23.4 & 6.7 & 2.6 \\
\hline & 470 & 0.9 & 85.8 & 10.3 & 53.2 & 21.4 & 12.5 & 1.7 & 1.8 \\
\hline \multirow{3}{*}{ 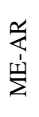 } & 450 & 1.2 & 46.2 & 2.8 & 24.3 & 18.3 & 38.5 & $\begin{array}{c}15 \\
3\end{array}$ & 2.0 \\
\hline & 460 & 1.1 & 79.0 & 6.1 & 47.9 & 24.2 & 19.3 & 1.7 & 1.9 \\
\hline & 470 & 1.9 & 90.2 & 9.3 & 60.0 & 19.9 & 8.5 & 1.3 & 2.9 \\
\hline
\end{tabular}

The yield of light fraction reached about 60 wt $\%$, the yield of liquid fractions $\left(\mathrm{BP}<350^{\circ} \mathrm{C}\right)$ reached approximately $80 \mathrm{wt} \%$ in the hydrocracking for ME-AR. In the case of TB$\mathrm{AR}$, the amount of residual fraction $\left(\mathrm{BP}>350^{\circ} \mathrm{C}\right)$, was decreased from $43.3 \mathrm{wt} \%$ to $9.4 \mathrm{wt} \%$, when the hydrocracking temperature increased. This result was effectively.

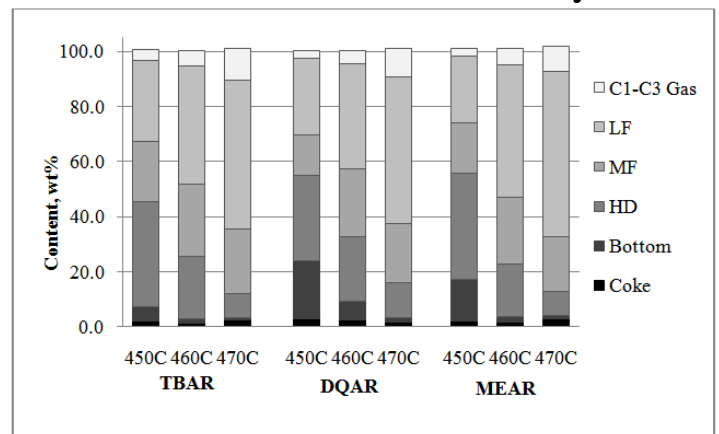

Figure 2. The change of distribution for products after the run of hydrocracking.

Hydrocracking reactions of all $\mathrm{AR}$ samples at the highest temperature of $470^{\circ} \mathrm{C}$ in the present study provided the largest amount of consumed hydrogen and the yield of light fraction, consequently, and the lowest yield of heavy, bottom and residual fractions. In particular, the consumption amount of hydrogen gas for hydrocracking conversion was the highest for the atmospheric residue of Middle East oil (ME-AR). It should be explained by the lowest $\mathrm{H} / \mathrm{C}$ atomic ratio of corresponding feedstock. The $\mathrm{H} / \mathrm{C}$ ratio of ME-AR was the lowest (1.66) as shown in Table 1 .

Figure 2 illustrated the change of distribution for products after this hydrocracking series. It was evident that in increasing the temperature, was lightened the products. The distribution of liquid fraction $\left(<350^{\circ} \mathrm{C}\right)$ including gaseous product, changed from 45.4-55.0 wt $\%$ to 84.9-89.2 wt\%, when temperature increase from $450^{\circ} \mathrm{C}$ to $470^{\circ} \mathrm{C}$. The excess of $100 \mathrm{wt} \%$ provided a consumption amount of hydrogen.

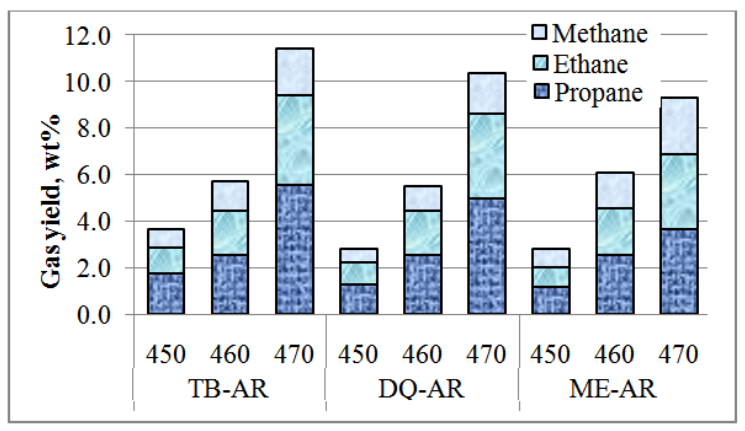

Figure 3 . The yield of $\mathrm{C}_{1}-\mathrm{C}_{3}$ gases after hydrocracking

Yields of gaseous products after catalytic hydrocracking are illustrated in Figure 3. With the atmospheric distillable residue of Tamsagbulag crude oil (TB-AR), the highest yield of gaseous products was obtained after the run of catalytic hydrocracking at the temperatures of $450^{\circ} \mathrm{C}$ and $470^{\circ} \mathrm{C}$. It was evident that with increasing temperature the yield of total $\mathrm{C}_{1}-\mathrm{C}_{3}$ gases increased for all AR samples. Also the methane content in gaseous products was the lowest, but the propane content was the highest after every run of catalytic hydrocracking. 


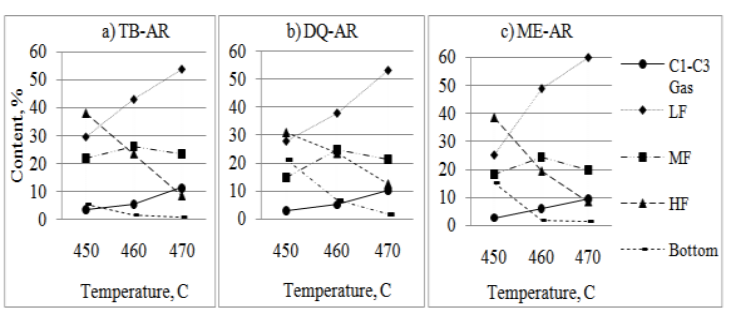

Figure 4. Relationship between content of products and hydrocracking temperature

Figure 4 summarizes a dependence of total product distribution on hydrocracking temperature for TB-AR, DQ-AR and ME-AR samples. As reaction temperature increased, a yield of light fraction (LF) increased, but yields of heavy fractions (HF) and bottom decreased respectively in all runs. Also a formation of gaseous products occurred significantly with increasing temperature. However, a change in the yield of middle fraction was not clearly observed when a reaction temperature increased. It is suggested that an effect of temperature on cracking reactivity of larger molecules (in particular, heavy fraction) was higher compared to that of smaller molecules (MF).

Table 4. Content of fractions and n-paraffins, in hydrocracking products, analyzed by GC-FID [wt $\%$ ]

\begin{tabular}{|c|c|c|c|c|c|c|c|c|c|}
\hline \multirow{2}{*}{$\begin{array}{l}\text { Samples } \\
\text { Temperature }\end{array}$} & \multicolumn{3}{|c|}{ TB-AR } & \multicolumn{3}{|c|}{ DQ-AR } & \multicolumn{3}{|c|}{ ME-AR } \\
\hline & $450^{\circ} \mathrm{C}$ & $460^{\circ} \mathrm{C}$ & $470^{\circ} \mathrm{C}$ & $450^{\circ} \mathrm{C}$ & $460^{\circ} \mathrm{C}$ & $470^{\circ} \mathrm{C}$ & $450^{\circ} \mathrm{C}$ & $460^{\circ} \mathrm{C}$ & $470^{\circ} \mathrm{C}$ \\
\hline & \multicolumn{6}{|c|}{ on middle distillate of hydrocracking product } & \multirow[b]{2}{*}{0.1} & \multirow[b]{2}{*}{0.2} & \multirow[b]{2}{*}{0.2} \\
\hline$<151^{\circ} \mathrm{C}$ & - & - & - & - & 0.1 & 0.1 & & & \\
\hline$<254^{\circ} \mathrm{C}$ & 42.8 & 32.6 & 29.7 & 46.8 & 40.9 & 35.4 & 36.0 & 33.4 & 27.9 \\
\hline$<344^{\circ} \mathrm{C}$ & 53.9 & 60.1 & 61.9 & 48.1 & 54.9 & 59.6 & 59.5 & 60.1 & 63.6 \\
\hline$>344^{\circ} \mathrm{C}$ & 3.3 & 7.3 & 8.4 & 5.1 & 4.1 & 4.9 & 4.4 & 6.3 & 8.3 \\
\hline$n$.paraffins & 46.3 & 46.1 & 45.9 & 46.7 & 46.5 & 45.0 & 21.2 & 26.1 & 25.9 \\
\hline \multicolumn{7}{|c|}{ on heavy distillate of hydrocracking product } & & \multirow[b]{2}{*}{0.9} & \multirow[b]{2}{*}{4.7} \\
\hline$<254^{\circ} \mathrm{C}$ & 0.2 & 1.2 & 0.5 & 0.2 & 1.7 & 1.5 & & & \\
\hline$<344^{\circ} \mathrm{C}$ & 34.3 & 21.3 & 13.4 & 27.3 & 30.3 & 14.4 & 22.3 & 23.4 & 15.1 \\
\hline$<496^{\circ} \mathrm{C}$ & 63.4 & 71.3 & 81.0 & 70.8 & 65.4 & 78.3 & 72.4 & 72.6 & 76.6 \\
\hline$>496^{\circ} \mathrm{C}$ & 2.1 & 6.2 & 5.1 & 1.7 & 2.6 & 5.8 & 3.9 & 3.1 & 3.6 \\
\hline$n$.paraffins & 41.1 & 37.3 & 29.4 & 40.4 & 37.7 & 32.4 & 18.6 & 20.5 & 14.8 \\
\hline
\end{tabular}

The content of subfractions and nparaffin on middle and heavy distillates of hydrocracking product were shown in Table 4. The contents of n-paraffins for TB-AR, DQ-AR were similar, but ME-AR's was around 2 times lower than others, after hydrocracking series. This result related from hydrocarbons structure of feedstock.

\section{Conclusions}

Atmospheric residue of Tamsagbulag crude oil (TB-AR) was tested for catalytic hydro cracking in the first time. In order to compare a cracking reactivity of Mongolian crude oil, the Chinese Daqing (DQ-AR) and Middle East (ME-AR) samples were tested under the following conditions: over $200 \mathrm{mg}$ of commercial $\mathrm{NiMo} / \mathrm{Al}_{2} \mathrm{O}_{3}$ catalyst at the temperature of $450^{\circ} \mathrm{C}-470^{\circ} \mathrm{C}$ for 2 hours under hydrogen pressure of $10 \mathrm{MPa}$. Some conclusions can be drawn as follows:

(1) In the hydrocracking of atmospheric residue from Tamsagbulag crude oil (TB-AR) the yield of the gas and liquid products $\left(\mathrm{BP}<350^{\circ} \mathrm{C}\right)$ increased sharply at $460^{\circ} \mathrm{C}$.

(2) The consumption amount of hydrogen gas for hydro cracking conversion was the highest for the atmospheric residue of Middle East oil (ME-AR). It should be explained by the lowest $\mathrm{H} / \mathrm{C}$ atomic ratio of corresponding feedstock.

(3) The contents of n-paraffins for TB-AR, DQ-AR were similar, but ME-AR's was around 2 times lower than others, after hydrocracking series. This result related to there's hydrocarbons structure.

\section{References}

1. B. Shirchin, E. Nordov, D. Ganzorig, Ts. Tugsuu. Chemical and technological characteristics of Tamsagbulag oil [J]. Work in research, NUM. 2001, 177 (4), pp 3140

2. J. Sainbayar, D.Monkhoobor, G.Sukhdorj. Study on some microelement's in Tamsagbulag oil by ICP-Method [C]. Proceeding of the Mongolian Academy of Sciences, ISBN 99929-5-675-5, 2009192 (2), pp 37-45 
3. D. Monkhoobor, A. Sainbayar, M. Tuya., Geochemical study on Tamsagbulag and Zuunbayan oils, Mongolia [J]. Chemistry and Chemical technology, ISSN-18188478, 2004239 (5), pp 156-168

4. Adiya Sainbayar. A study on hydrocarbons composition of light fractions of Mongolian petroleum [D]. Ulaanbaatar, Mongolia: National University of Mongolia. 2005.
5. Masato Kouzu, Yasunori Kuriki, and Yoshikazu Sugimoto. Catalytic Hydrocracking of Petroleum Residue over Carbon-Supported NickelMolybdenum Sulfide [J]. Energy \& fuels, 19 (3) pp 725-730. 2005.

6. Sugimoto Yoshikazu, Youichi Aihara, and Akimitsu Matsumura. Processing of Middle East crude with Canadian oil sands bitumen-derived synthetic crude oil [J]. Journal of the Japan petroleum institute, vol 49 (1) pp 1-12. 2006. 